SUPPORTING INFORMATION

\title{
Synthesis of Polymandelide: A Degradable Polylactide Derivative with Polystyrene-like Properties.
}

Tianqi Liu, Tara L. Simmons, David A. Bohnsack, Michael E. Mackay, Milton R.

Smith, III and Gregory L. Baker*

Department of Chemistry Michigan State University, East Lansing, Michigan 48824, and Department of Chemical Engineering and Materials Science, Michigan State

University, East Lansing, Michigan 48824-1226

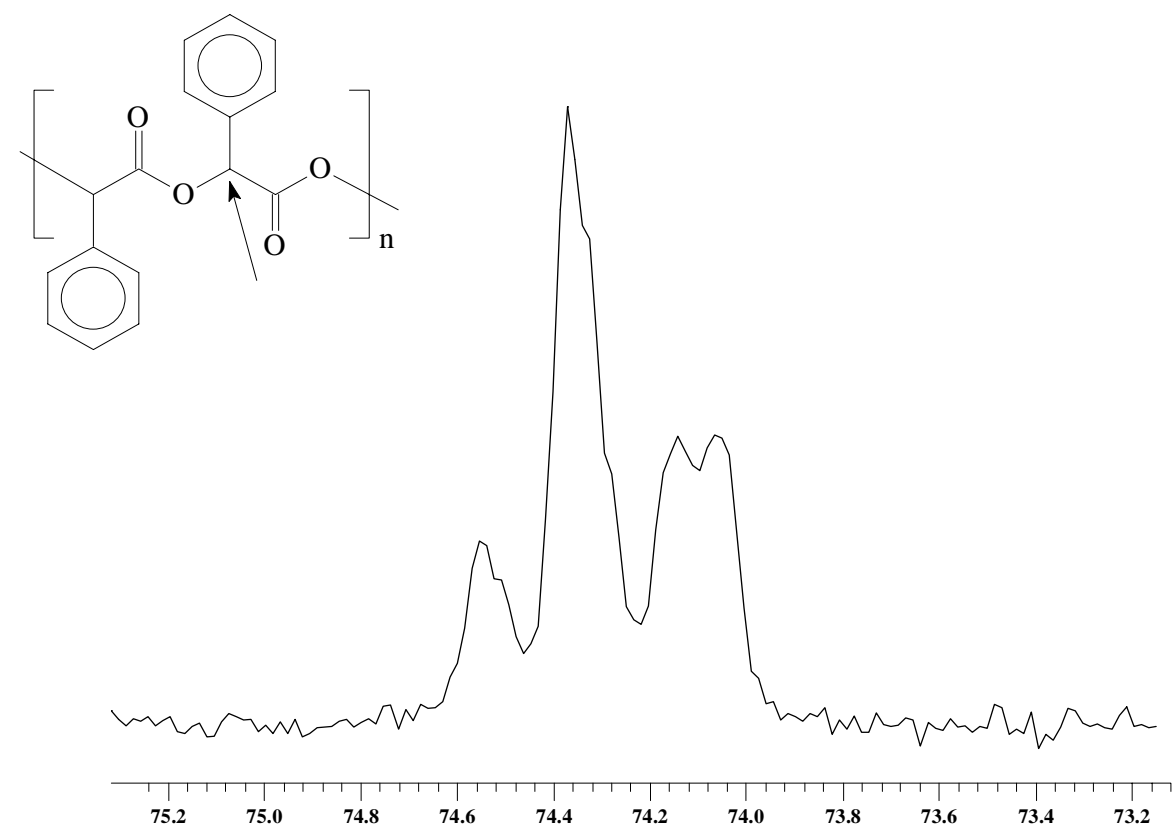

Figure S-1. $125 \mathrm{MHz}{ }^{13} \mathrm{C} \mathrm{NMR}$ data showing the methine region of the spectrum for polymandelide prepared by melt polymerization of a mixture of $75 \%$ meso-mandelide and $25 \%$ rac-mandelide at $160{ }^{\circ} \mathrm{C}$. The data were collected in $d^{6}$-DMSO at $30^{\circ} \mathrm{C}$. 


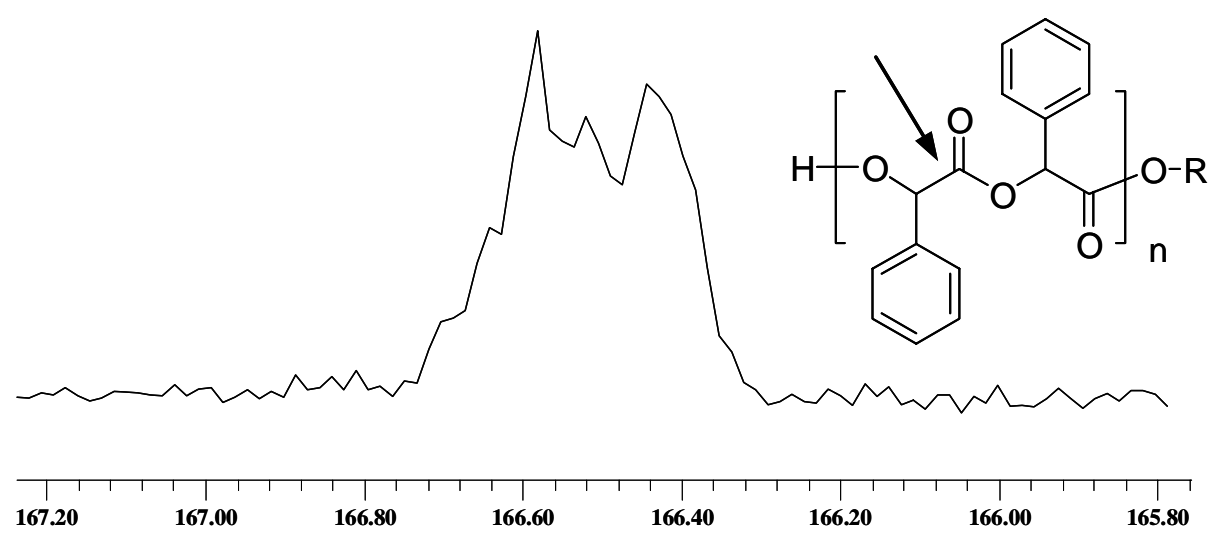

Figure S-2. $125 \mathrm{MHz}{ }^{13} \mathrm{C}$ NMR data showing the carbonyl region of the spectrum for polymandelide prepared by melt polymerization of a mixture of $75 \%$ meso-mandelide and $25 \%$ rac-mandelide at $160{ }^{\circ} \mathrm{C}$. The data were collected in $d^{6}$-DMSO at $30^{\circ} \mathrm{C}$.

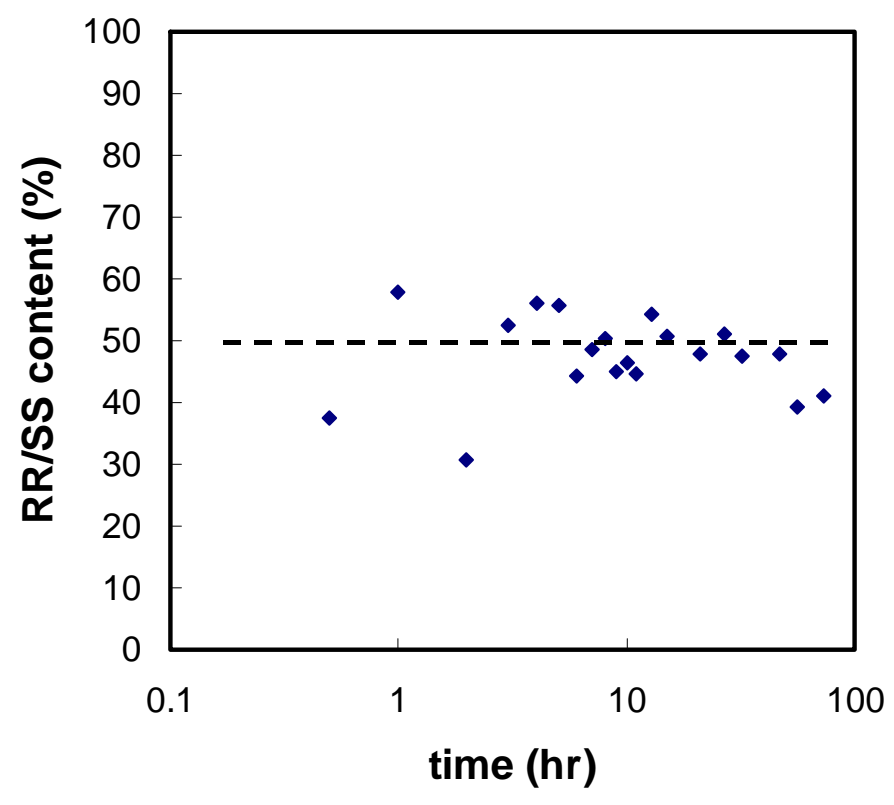

Figure S-3. Data showing the composition of the monomer pool during the solution polymerization of mandelide in $\mathrm{CH}_{3} \mathrm{CN}$ at $70^{\circ} \mathrm{C}$ under argon. The initial monomer composition was a 3:1 mixture of meso- and rac-mandelide. Conditions: [mandelide]:[Sn(2ethylhexanoate $\left.)_{2}\right]$ : $[\mathrm{BBA}]=100: 1: 1$; $[$ mandelide $]=0.93 \mathrm{~mol} / \mathrm{L}$. 